\title{
The Effect of Nitrogen Limitation on Catabolite Repression of Amidase, Histidase and Urocanase in Pseudomonas aeruginosa
}

\author{
By J. R. POTTS* AND PATRICIA H. CLARKE \\ Department of Biochemistry, University College London, London WCIE $6 B T$
}

(Received I5 September 1975)

\begin{abstract}
SUMMARY
In Pseudomonas aeruginosa, the synthesis of histidase, urocanase and amidase is severely repressed when succinate is added to a culture growing in pyruvate + ammonium salts medium. When growth is nitrogen-limited, catabolite repression by succinate of histidase and urocanase synthesis does not occur but succinate repression of amidase synthesis persists. Amidase synthesis is not regulated in the same way as histidase synthesis by the availability of other nitrogen compounds for growth.

Growth of $P$. aeruginosa strain PACI in succinate + histidine media is nitrogenlimited since this strain is defective in a histidine transport system. When methylammonium chloride is added to succinate + histidine media, growth inhibition occurs. Mutants isolated from succinate + histidine + methylammonium chloride plates were found to be resistant to catabolite repression by succinate even in ammonium salts media. It is suggested that the hut genes of $P$. aeruginosa may be regulated in the same way as in Klebsiella aerogenes, by induction by urocanate and activation by either the cyclic AMP-dependent activator protein or by glutamine synthetase.
\end{abstract}

\section{INTRODUCTION}

Many catabolic enzymes are induced by their substrates and may also be subject to repression by other cell metabolites. In Pseudomonas aeruginosa, amidase is induced by acetamide and is severely repressed by succinate, by other intermediates of the tricarboxylic acid cycle, and by acetate which is one of the products of the action of the enzyme on acetamide (Brammar \& Clarke, 1964). The other product, ammonia, does not appear to have any effect on the rate of amidase synthesis (Kelly, 196I). Mutants partially resistant to catabolite repression by succinate have been isolated from plates containing lactamide (a poor substrate) as the nitrogen source, and succinate as the carbon source. Catabolite repressionresistant mutants isolated under these conditions of nitrogen-limited growth were found to carry mutations in genes which were unlinked to the amidase structural and regulator genes $a m i E$ and $a m i R$, and some of these had lower rates of growth on succinate (Smyth \& Clarke, I975a). However, some catabolite repression-resistant mutants isolated by another selection method were found to have mutations very closely linked to the amidase genes and these were presumed by Smyth \& Clarke (1975b) to be promoter mutants.

Induced amidase synthesis by the wild-type strain, and amidase synthesis by constitutive strains, is stimulated by cyclic $3^{\prime}: 5^{\prime}$-adenosine monophosphate (c-AMP) but one of the 'up promoter' mutants with a very high rate of amidase synthesis was insensitive to stimulation by c-AMP. Although it was not possible to relieve the severe catabolite repression of

* Present address: Process Investigation Department, Glaxo Laboratories Ltd, Ulverston LAI2 9DR, Cumbria. 
amidase synthesis resulting from the addition of succinate to cultures growing exponentially in pyruvate +ammonium salts medium, it was possible to get partial relief of the less severe repression produced by lactate, by adding c-AMP to the cultures (Smyth \& Clarke, 1975a). These findings suggested that the amidase genes, and perhaps genes for other catabolic enzymes of $P$. aeruginosa, may be under the same general regulation of transcription by an activator protein modified by c-AMP as occurs in Escherichia coli (de Crombrugghe et al., I97I). Arst \& Cove (1973) have pointed out that in fungi many enzymes required for the catabolism of nitrogen-containing compounds are subject to repression by carbon compounds such as glucose, and, in addition, are repressed by ammonia and other nitrogenous compounds. Hynes (1970, 1972, 1974) has observed that an acetamidase produced by Aspergillus nidulans is subject to both ammonia and glucose repression.

Histidase in $P$. aeruginosa is induced by urocanate and repressed by succinate (Lessie \& Neidhardt, 1967). The pathway for histidine catabolism is shown in Fig. I. The genes for the first two enzymes are regulated co-ordinately and both histidase and urocanase are repressed when succinate is added to a culture growing exponentially in pyruvate + ammonium salts medium in the presence of histidine or urocanate (Potts, 1975).

In Klebsiella aerogenes, histidase synthesis is repressed by glucose in a medium containing both histidine and ammonium salts but not when histidine is the sole nitrogen source (Prival \& Magasanik, I97I). The interaction of the regulatory mechanisms which control the expression of the hut (histidine utilization) genes in K. aerogenes and Salmonella typhimurium, under conditions of differing carbon and nitrogen availability, has been intensively studied. Relief of catabolite repression by glucose during nitrogen-limited growth has been related to the increased level of glutamine synthetase which is required for ammonia assimilation when the ammonia concentration is low. Glutamine synthetase is thought to act as an activator protein for the positive control of transcription of the hut genes (Prival, Brenchley \& Magasanik, I973; Tyler, Deleo \& Magasanik, 1974).

The hut operon is thought to be regulated in three ways. The hutC product is an operonspecific represser which responds to the inducer, urocanate. However, transcription also requires an activator protein which may be either the c-AMP receptor (CRP) protein in its active conformation, or alternatively glutamine synthetase in its enzymically active nonadenylated form (Magasanik et al., 1974). Thus, in a medium with a high concentration of ammonia and a non-repressing carbon source, the level of glutamine synthetase is low and transcription of the hut genes is activated by the CRP protein. During nitrogen-limited growth the level of glutamine synthetase is high, so that transcription of the hut genes can still be activated even in the presence of a compound such as glucose.

We have compared catabolite repression of amidase and histidase in $P$. aeruginosa growing in an ammonium salts medium and in a nitrogen-limited medium. Strain PACr, unlike most strains of $P$. aeruginosa, is unable to utilize L-histidine as a carbon and energy source for growth although it can utilize this amino acid as a nitrogen source. Potts \& Clarke (1974) showed that strain PACI was defective in histidine transport but could take up histidine at a rate sufficient to satisfy the requirements of a histidine auxotroph or to provide a nitrogen source if pyruvate or succinate were provided as carbon sources. Strain PACI grows slowly in pyruvate + histidine medium and since the growth rate is determined by the rate of uptake of histidine the cultures are growing under nitrogen-limited conditions. The histidine transport defect of strain PACI thus provides a convenient means of examining the synthesis of amidase, histidase and urocanase during nitrogen-limited growth and of studying the effects of compounds such as succinate which are known to repress these enzymes in a pyruvate +ammonium salts medium. 


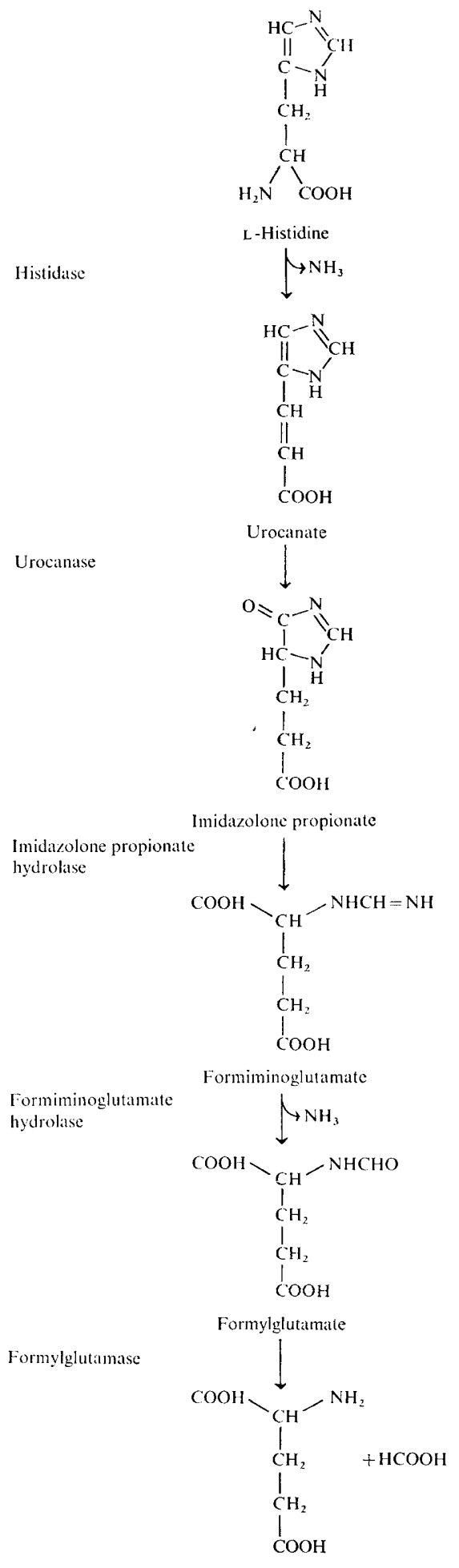

L-Glutamate + formate

Fig. I. Pathway for histidine catabolism. 
Table I. Strains of Pseudomonas aeruginosa

\begin{tabular}{|c|c|c|c|c|}
\hline Strain no. & $\begin{array}{l}\text { Parent } \\
\text { strain }\end{array}$ & Derivation & Phenotype & Reference \\
\hline PACI (wild type) & - & 一 & $\begin{array}{l}\text { Amidase inducible, histidase } \\
\text { inducible, } \mathrm{S} / \mathrm{H}^{+}, \mathrm{H}^{-}\end{array}$ & Kelly \& Clarke (1962) \\
\hline PACI I I & PACI & Spontaneous & $\begin{array}{l}\text { Amidase constitutive, histidase } \\
\text { inducible, } \mathrm{S} / \mathrm{H}^{+}, \mathrm{H}^{-}\end{array}$ & $\begin{array}{l}\text { Brammar, Clarke \& } \\
\text { Skinner (1967) }\end{array}$ \\
\hline PAC569 & PACI & Spontaneous & $\begin{array}{l}\text { Amidase inducible, histidase consti- } \\
\text { tutive, } \mathrm{S} / \mathrm{H}^{+}, \mathrm{H}^{-}\end{array}$ & This paper \\
\hline $\operatorname{PAC} 570$ & PAC569 & NTG & $\begin{array}{l}\text { Amidase inducible, histidase consti- } \\
\text { tutive, } \mathbf{S} / \mathbf{H}^{+}, \mathbf{H}^{+}\end{array}$ & This paper \\
\hline PAC57I & PAC570 & Spontaneous & $\begin{array}{l}\text { Amidase inducible, histidase consti- } \\
\text { tutive, } \mathrm{S} / \mathrm{H}^{+}, \mathrm{H}^{+}, \text {MAC-resistant, } \\
\text { succinate repression-resistant }\end{array}$ & This paper \\
\hline
\end{tabular}

$\mathrm{S} / \mathrm{H}^{+}$, growth on minimal agar plates with succinate $(\mathrm{I} \% \mathrm{w} / \mathrm{v})+$ histidine $(0.02 \%, \mathrm{w} / \mathrm{v}) ; \mathbf{H}^{+}$, growth on minimal agar plates with histidine $(0 \cdot 2 \%, \mathrm{w} / \mathrm{v}) ; \mathrm{MAC}$, methylammonium chloride.

\section{METHODS}

Organisms. The bacterial strains were all derived from the wild-type strain of $P$. aeruginosa, PACI, and are listed in Table I. The isolation of strain PACIII (CI I) was described by Brammar, Clarke \& Skinner (1967). Strain PAC569 was isolated as a spontaneous mutant from PACI on succinate $(\mathrm{I} \cdot 0 \% \mathrm{w} / \mathrm{v})+\mathrm{L}$-histidine $(0.02 \%, \mathrm{w} / \mathrm{v})+$ pyrophosphate (IO mM) agar plates which were incubated at $43{ }^{\circ} \mathrm{C}$ as described by Potts \& Clarke (1974). Strain PAC570 was isolated following $N$-methyl- $N^{\prime}$-nitro- $N$-nitrosoguanidine (NTG) mutation of strain PAC569 (Brammar et al., 1967) and selection on succinate $(\mathrm{I} \cdot 0 \%, \mathrm{w} / \mathrm{v})+$ histidine $(0.02 \%$, $(\mathrm{w} / \mathrm{v})+$ pyrophosphate $(20 \mathrm{~mm})$ plates incubated at $37^{\circ} \mathrm{C}$. Strain PAC57I was isolated as a spontaneous mutant from PAC570 on succinate $(\mathrm{I} \cdot 0 \% \mathrm{w} / \mathrm{v})+\mathrm{L}-\mathrm{histidine}(0.02 \%, \mathrm{w} / \mathrm{v})+$ methylammonium chloride $(0.5 \%, \mathrm{w} / \mathrm{v})$ agar plates after incubation at $37^{\circ} \mathrm{C}$.

Media. The media used were based on the minimal salt medium described by Brammar \& Clarke (1964). The differential rates of amidase, histidase and urocanase synthesis were measured before and after addition of succinate $(\mathrm{I} \cdot 0 \% \mathrm{w} / \mathrm{v})$ to minimal salt medium containing pyruvate $(\mathrm{I} \cdot \mathrm{O} \% \mathrm{w} / \mathrm{v})$. Ammonium sulphate was included in this medium where appropriate to give a final concentration of $0 . \mathrm{I} \%(\mathrm{w} / \mathrm{v})$. L-Histidine was sterilized by membrane filtration and added to give a concentration in liquid medium of $0.2 \%(\mathrm{w} / \mathrm{v})$. Methylammonium chloride was also sterilized separately and added to give a concentration of $0 . \mathrm{I} \%$ (w/v). All other media were as described by Brammar et al. (I967).

Growth conditions. Cultures for measuring rates of enzyme synthesis were grown in Erlenmeyer flasks of 100 or $250 \mathrm{ml}$ capacity and containing 20 or $50 \mathrm{ml}$ medium respectively, and incubated at $37^{\circ} \mathrm{C}$ using a water bath fitted with a mechanical shaker. Samples (I or $2 \mathrm{ml}$ ) were withdrawn at regular intervals for the measurement of growth and enzyme activity.

Growth measurements. Growth was followed by measuring the extinction at $670 \mathrm{~nm}$ of a suspension of bacteria with a Unicam SP60o spectrophotometer. A standard curve was used to convert readings to bacterial dry weight.

Enzyme assays. Amidase activity of suspensions was measured by the hydroxamate method described by Brammar \& Clarke (I964). The bacteria were resuspended in 0.I M-tris buffer $\mathrm{pH} 7 \cdot 2$. Amidase activity was defined as $\mu \mathrm{mol}$ acethydroxamate produced/min by I $\mathrm{ml}$ bacterial suspension. 
Histidase and urocanase activities were measured in cell-free extracts prepared by sub-

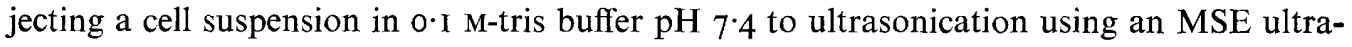
sonic oscillator. Debris was removed by centrifugation at $38000 \mathrm{~g}$ for $10 \mathrm{~min}$. The temperature was maintained at $4{ }^{\circ} \mathrm{C}$ throughout.

Histidase activity was determined by measuring the rate of formation of urocanate from L-histidine at $37^{\circ} \mathrm{C}$ and $\mathrm{pH} \mathrm{9.2} \mathrm{(Lessie} \mathrm{\&} \mathrm{Neidhardt,} \mathrm{1967).} \mathrm{This} \mathrm{was} \mathrm{accomplished} \mathrm{by} \mathrm{measur-}$ ing the rate of increase in $E_{277}$ with a Unicam SP800 spectrophotometer. Histidase specific activity was expressed as $\mu \mathrm{mol}$ urocanate formed/min by $\mathrm{I} \mathrm{mg}$ protein. In the comparison of the differential rates of histidase and amidase synthesis in growing cultures, the histidase activity is calculated as the product of the specific activity and the bacterial dry weight.

Urocanase activity was determined spectrophotometrically by measuring the rate of degradation of urocanate, based on the method of Lessie \& Neidhardt (1967). The $E_{277}$ was followed during incubation at $\mathrm{pH} 7.4$ and $37^{\circ} \mathrm{C}$ using an initial urocanate concentration of $0.06 \mathrm{~mm}$. Urocanase specific activity was expressed as $\mu \mathrm{mol}$ urocanate degraded $/ \mathrm{min}$ by I $\mathrm{mg}$ protein.

Protein assays. The method of Lowry et al. (195I) was used to determine the protein concentration in cell-free extracts. Bovine plasma albumin was the standard.

\section{RESULTS}

\section{Succinate repression during nitrogen-limited growth}

Pseudomonas aeruginosa strain PACI was grown in pyruvate + ammonium salts medium with histidine $(25 \mathrm{~mm})$ added to induce histidase synthesis. Soon after the addition of succinate ( $25 \mathrm{mM}$ ), at the time indicated by the arrow (Fig. 2), the synthesis of histidase was repressed $>90 \%$ (Smyth, 1974). This is virtually identical to the extent of succinate repression of amidase synthesis in this medium (Smyth \& Clarke, 1975a). Synthesis of urocanase has been found to be co-ordinate with histidase under all growth conditions (Potts, 1975) and urocanase was repressed to the same extent as histidase in these experiments. Strain PACI was then grown in pyruvate + histidine medium under conditions of nitrogen-limitation. When succinate was added to this culture no repression of histidase or urocanase synthesis could be detected (Fig. 3). It was therefore clear that in this medium, when the growth rate was limited by the rate of uptake of histidine, there was complete relief from catabolite repression by succinate.

Although the growth of strain PACI is nitrogen-limited in pyruvate + histidine medium, the rate of histidine uptake is quite sufficient to induce the synthesis of histidase and urocanase. It was therefore possible to use this medium to examine the effect of succinate on histidase and urocanase synthesis. To see whether there was any relief of succinate repression of amidase synthesis under conditions of nitrogen limitation, it was preferable to use an amidase constitutive strain to avoid any complications which might have been due to effects on amide uptake in this medium. In the following experiments the strain used was PACrII, which is constitutive for amidase synthesis and sensitive to catabolite repression, but inducible for histidase and urocanase synthesis.

Strain PACI I I was grown in pyruvate + ammonium salts medium and when the bacterial growth had reached $0.12 \mathrm{mg}$ dry wt bacteria $/ \mathrm{ml}$ the culture was divided into three separate flasks. One was kept as control, to the second was added succinate to give a final concentration of $\mathrm{I} \cdot 0 \%(\mathrm{w} / \mathrm{v})$, and to the third was added the same amount of succinate together with ammonium sulphate to give a final concentration of $0.1 \%(w / v)$. When succinate was added alone there was no increase in the growth rate, confirming that growth was limited by the 


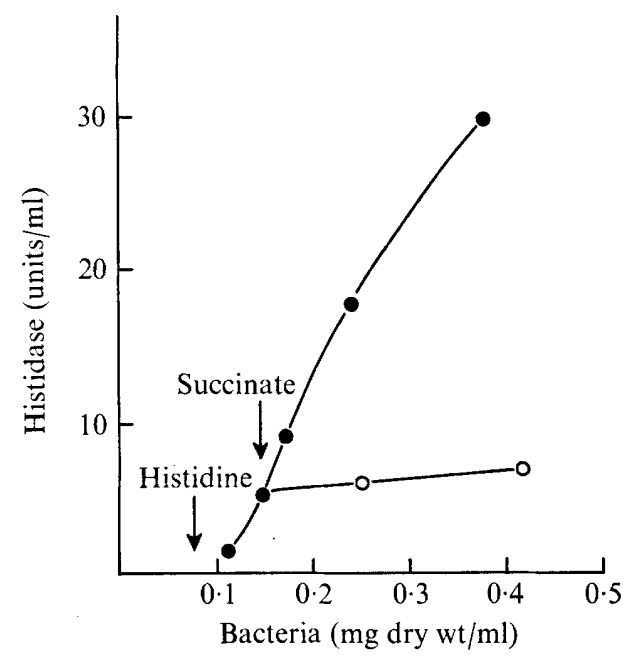

Fig. 2

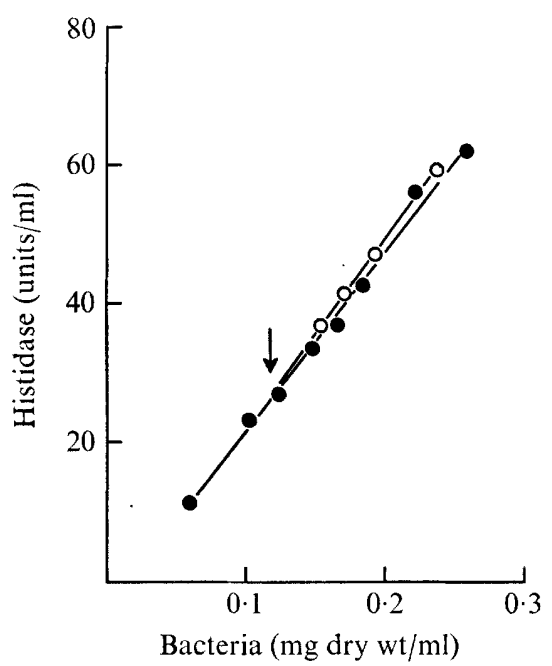

Fig. 3

Fig. 2. The effect of succinate on the differential rate of histidase synthesis by $\boldsymbol{P}$. aeruginosa strain PACI growing exponentially in pyruvate + ammonium salts medium. Histidine (25 mM) was added early in growth as indicated by the first arrow. At the bacterial density indicated by the second arrow the culture was divided into two flasks. Succinate $(25 \mathrm{~mm})$ was added to one flask $(O)$ and the other flask served as the control (0).

Fig. 3. The effect of succinate on the differential rate of histidase synthesis by $P$. aeruginosa strain PACI growing exponentially in pyruvate + histidine medium. At the bacterial density indicated by the arrow the culture was divided into two flasks. Succinate $(\mathrm{I} \cdot \mathrm{O} \% \mathrm{w} / \mathrm{v})$ was added to one flask $(\mathrm{O})$ and the other flask served as the control (O).

uptake of histidine (Fig. 4a). If succinate is added to a culture growing in pyruvate+ ammonium salts medium there is a significant increase in growth rate in a very short time (Smyth \& Clarke, 1975a). When ammonium sulphate was added together with the succinate, the nitrogen limitation on growth was removed and there was an immediate increase in growth rate. Figure $4(b)$ shows that, as had been found previously for strain PACI, there was no effect on the differential rate of histidase synthesis when succinate was added alone, but when ammonium sulphate was added at the same time there was a rapid and severe repression of enzyme synthesis. In contrast to this, the repression of amidase synthesis was severe and rapid irrespective of whether ammonium sulphate had been added with the succinate (Fig. 4c). From these results it can be seen that catabolite repression of amidase synthesis occurs when growth is nitrogen-limited as well as when excess ammonium ions are present. Unlike amidase, histidase appears insensitive to repression by succinate when growth is nitrogen-limited and is sensitive to succinate repression only in the presence of a high concentration of ammonium salts.

Although we had shown that amidase synthesis was still subject to catabolite repression when growth was nitrogen-limited and was not relieved from carbon repression by a low availability of nitrogen, this did not rule out the possibility that a high ammonium ion concentration might have a direct effect on the rate of amidase synthesis. This could be examined by comparing the maximum differential rate of amidase synthesis in pyruvate + histidine medium with that in pyruvate +ammonium salts medium. If ammonia exerted a direct repressing effect on the rate of amidase synthesis it would be predicted that the maximum rate of amidase synthesis in the medium containing ammonium salts would be substantially 

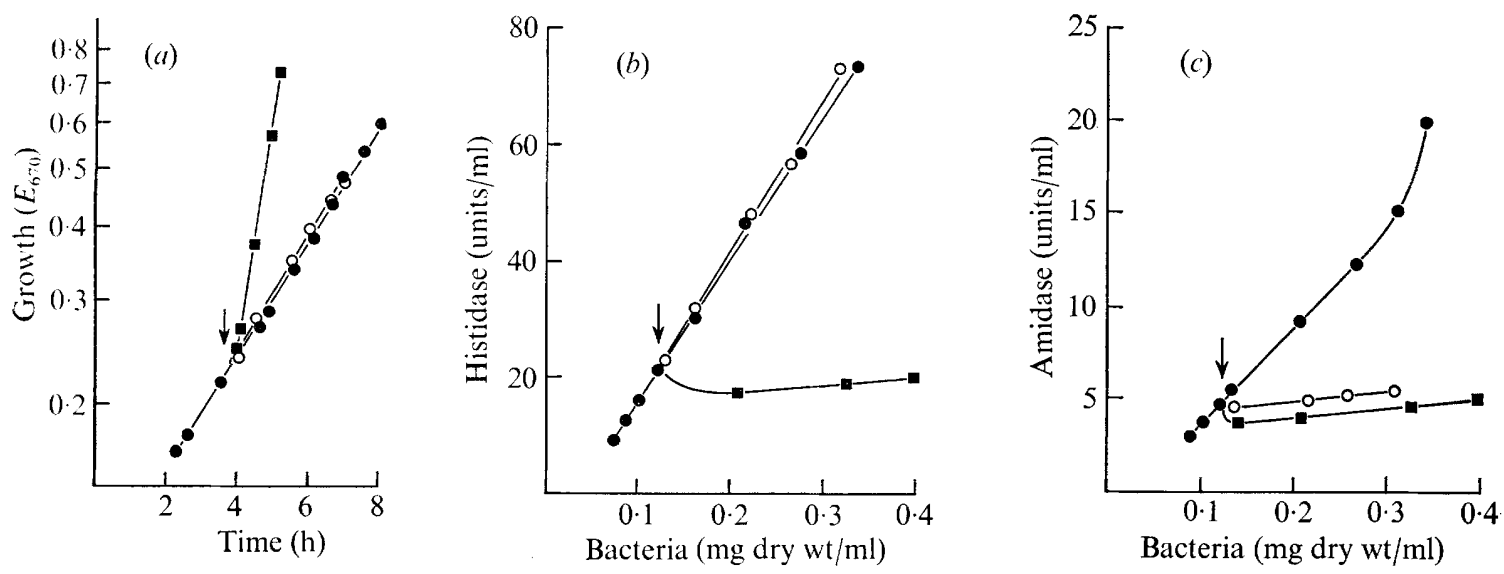

Fig. 4. The effects of succinate and ammonium salts on $(a)$ growth, $(b)$ histidase synthesis and (c) amidase synthesis, by $P$. aeruginosa strain PACI I I growing exponentially in pyruvate + histidine medium. At the time indicated by the arrow the culture was divided into three flasks. Succinate $(\mathrm{I} \cdot 0 \%, \mathrm{w} / \mathrm{v})$ was added to one flask $(\mathrm{O})$, succinate $(\mathrm{I} \cdot 0 \%, \mathrm{w} / \mathrm{V})+$ ammonium sulphate $(0 \cdot \mathrm{I} \%, \mathrm{w} / \mathrm{v})$ were added to a second flask ( $\square$ ), and the third flask was kept as the control (O).

lower than that in the nitrogen-limited medium. The maximum differential rate of amidase synthesis by strain PACIII is 45 units $/ \mathrm{mg}$ bacteria in pyruvate + ammonium salts medium (Smyth \& Clarke, 1975a). When the differential rate of amidase synthesis in pyruvate+ histidine medium was measured an identical value of 45 units/mg bacteria was recorded. For amidase synthesis, therefore, ammonia does not appear to exert a direct repressing effect.

\section{Isolation of catabolite repression-resistant mutants}

The persistence of catabolite repression by succinate during nitrogen-limited growth explained why we had been able to isolate catabolite repression-resistant mutants on succinate + lactamide minimal agar plates. The relief of catabolite repression by succinate of histidase synthesis under nitrogen limitation also explained why we had been unable to use succinate + histidine or succinate + urocanate plates to select catabolite repression-resistant mutants for the Hut pathway. A positive selection method of this sort is dependent on the possiblity of repressing an essential enzyme, in this case histidase or urocanase, below the threshold value required for growth to occur. We thought that it might be possible to add a non-metabolizable analogue of ammonia, such as methylammonium chloride, to a succinate + histidine medium and so reduce the rate of growth to a level which would allow the selection of derepressed mutants.

Growth of $P$. aeruginosa strain PACI I I on succinate + histidine medium, or on succinate + histidine plates, was almost completely inhibited by $0.1 \%(\mathrm{w} / \mathrm{v})$ methylammonium chloride. To test whether this growth inhibition was due, at least in part, to the potentiation of succinate repression by methylammonium chloride, the effect of this compound on repres. sion by succinate was examined in pyruvate + histidine medium. Figure 5 shows an experiment with PACI I carried out as before, but with methylammonium chloride added instead of ammonium sulphate. It can be seen that in the presence of methylammonium chloride there was considerable repression of histidase synthesis by succinate. However, there was also considerable growth inhibition, so that it is difficult to make exact comparisons with the effects of adding ammonium salts to this medium. With acetamide plates the addition of 


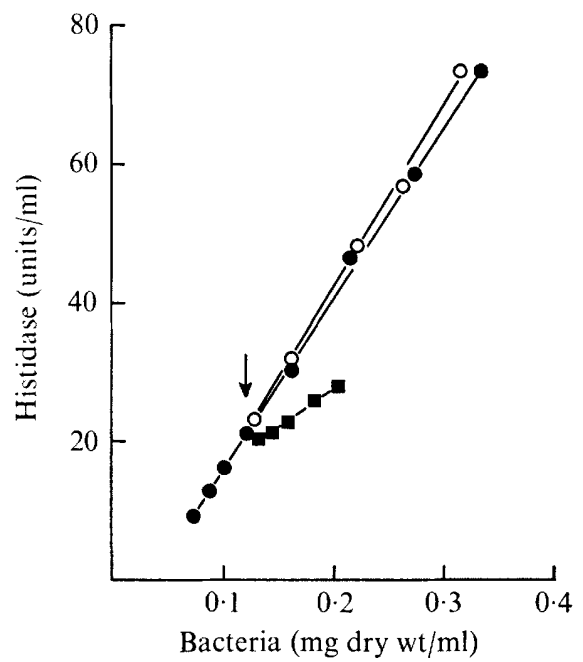

Fig. 5

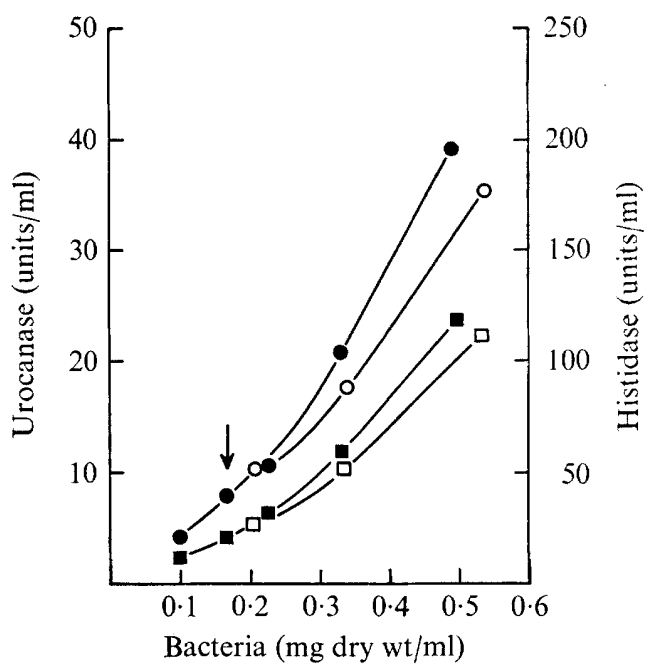

Fig. 6

Fig. 5. The effects of methylammonium chloride and succinate on the differential rate of histidase synthesis by $P$. aeruginosa strain PACI I growing exponentially in pyruvate + histidine medium. At the bacterial density indicated by the arrow the culture was divided into three flasks. Succinate $(\mathrm{I} \cdot 0 \%, \mathrm{~W} / \mathrm{v})$ was added to one flask $(\mathrm{O})$, succinate $(\mathrm{I} \cdot 0 \%, \mathrm{w} / \mathrm{V})+$ methylammonium chloride $(0.1 \%, w / v)$ were added to a second flask ( $\mathbf{m})$, and the third flask was kept as the control (O).

Fig. 6. The effect of succinate on the differential rates of histidase and urocanase synthesis by $P$. aeruginosa strain PAC57I growing exponentially in pyruvate + ammonium salts medium. At the bacterial density indicated by the arrow the culture was divided into two flasks. Succinate (I \%, w/v) was added to one flask (histidase, $O$; urocanase, $\square$ ) and the other flask was kept as the control (histidase, $\mathbf{0}$; urocanase, $\mathbf{\square}$ ).

$0.1 \%(w / v)$ methylammonium chloride resulted in a growth lag which was more pronounced with amidase constitutive strains when cultures had been previously grown in nutrient broth. When previously grown with acetamide, this lag occurred with both inducible and constitutive strains. After 2 to 3 days' incubation no differences could be seen.

Strain PAC57I was derived from PACI by several mutational steps. First we selected for faster growth on succinate + histidine + pyrophosphate plates at $43{ }^{\circ} \mathrm{C}$. This procedure gave the spontaneous mutant PAC569 which is histidase and urocanase constitutive, but still unable to take up histidine at a rate sufficient for it to be used as a carbon source. From strain PAC569, after mutagenesis with NTG, we selected strain PAC570 which is able to grow on histidine as the sole growth substrate although the rate of growth is rather low. Both PAC569 and PAC570 are repressed by succinate in an ammonium salts medium. Finally, we selected strain PAC57I from PAC570 on succinate + histidine + methylammonium chloride plates. (Table I.)

The rates of synthesis of both histidase and urocanase by strain PAC57I were hardly affected at all by the addition of succinate to a culture growing exponentially in pyruvate + ammonium salts medium (Fig. 6). This strain is therefore both constitutive and resistant to catabolite repression, and produces high levels of histidase and urocanase when grown with pyruvate as the carbon source in the presence of a good nitrogen source such as ammonia. The addition of methylammonium chloride to the succinate + histidine plates appears to have prevented the relief from catabolite repression by succinate which had previously been observed during nitrogen-limited growth, and made it possible for us to isolate catabolite 
repression-resistant mutants. The genetic basis of the resistance to catabolite repression of strain PAC57I has not been determined but it appears to result from a defect in the metabolism of succinate rather than to a mutation specific to the $h u t$ operon. Other mutants isolated in this way were also found to be defective in succinate metabolism and, as was predicted, they grew rather better than the parental strains on succinate + lactamide plates since the succinate defect also allowed partial derepression of amidase synthesis.

\section{DISCUSSION}

The synthesis of $\beta$-galactosidase and histidase in Klebsiella aerogenes is subject to severe catabolite repression by glucose in the presence of a good source of nitrogen. Under nitrogenlimited conditions, glucose repression of $\beta$-galactosidase remains but the repression of histidase is relieved (Prival \& Magasanik, I97I). We found a similar difference between the catabolite repression of amidase and histidase exerted by succinate in $P$. aeruginosa strain PACI. These results for the regulation of histidase synthesis confirm earlier observations made by Lessie \& Neidhardt (I967) on succinate repression of histidase in another strain of $P$. aeruginosa.

Our results for the regulation of the Hut enzymes in strain PACI suggest that they may be controlled in a similar manner to those of $K$. aerogenes, that is by induction by urocanate, and activation either by the CRP protein together with c-AMP or by glutamine synthetase in its non-adenylated form behaving as an activator protein. Indeed, it is thought that the activity of glutamine synthetase in $P$. aeruginosa and $P$. putida is regulated by adenylation in a similar manner to that found in the Enterobacteriacae (Tronick, Ciardi \& Stadtman, I973). The model proposed for $K$. aerogenes would fit the results we have obtained for histidase synthesis under different growth conditions. However, it is clear that this model cannot account for the regulation of amidase synthesis since there is no relief of the catabolite repression exerted by succinate during nitrogen-limited growth. The particular transport defect of strain PACI made it possible to measure both amidase and histidase synthesis in the same experiment so that nitrogen limitation could be assured. It is clearly not the case that the catabolic enzymes for all substrates capable of furnishing both carbon and nitrogen for growth are inevitably regulated by both carbon and nitrogen repression, as suggested by Arst \& Cove (1973) for Aspergillus nidulans. In particular, we have never observed any repression of amidase synthesis in $P$. aeruginosa which might have been a direct or indirect result of the presence of a high concentration of ammonium ions.

These results have highlighted similarities which may exist between the regulation of the hut genes in $P$. aeruginosa and $K$. aerogenes. However, unlike $K$. aerogenes and $P$. aeruginosa, histidase synthesis in some strains of Salmonella typhimurium remains sensitive to catabolite repression during nitrogen-limited growth. Salmonella typhimurium strain I5-59 was shown by Brill \& Magasanik (I969) to be unable to use histidine as a carbon source but able to use it as a nitrogen source. It was in this respect similar to $P$. aeruginosa $\mathrm{PACI}$, but differed in that growth with histidine as the nitrogen source was possible with certain carbon compounds but not with glucose which exerts severe catabolite repression on many $S$. typhimurium enzymes. This made it possible to isolate catabolite repression-resistant mutants from glucose + histidine plates, whereas to achieve sufficient selection pressure with $P$. aeruginosa it was necessary to add methylammonium chloride as well as a repressing carbon compound.

The differences between $K$. aerogenes, $P$. aeruginosa and $S$. typhimurium, with respect to relief from catabolite repression by carbon compounds in nitrogen-limited growth, emphasize the importance of the genetic background in comparing mechanisms of regulation 
of enzyme synthesis in different species. Although" the hut genes of S. typhimurium did not appear to respond in the same way as those of $K$. aerogenes, it was found by Prival \& Magasanik (I97I) that when the hut operon of S. typhimurium was transferred to K. aerogenes, glucose repression of histidase synthesis was relieved during nitrogen-limited growth. The inability to detect this relief in S. typhimurium strain I5-59 was due to the general genetic background rather than to the regulatory characteristics of the hut operon itself. Pseudomonas aeruginosa strains vary in sensitivity to catabolite repression by carbon compounds, and we are currently investigating the behaviour of catabolic genes transferred from one strain to another.

In $K$. aerogenes some mutants with defects in $g \ln A$, the structural gene for glutamine synthetase, are unable to grow in glucose + histidine medium since they are unable to escape from catabolite repression during nitrogen-limited growth. On the other hand, GlnC mutants, which are constitutive for glutamine synthetase, are resistant to glucose repression of both histidase and proline oxidase even with high ammonium ion concentrations (Prival et al., 1973). This suggests that mutations in $g l n$ genes in other organisms might also have pleiotropic effects on growth with amino acids. This may be of particular importance for Pseudomonas species which are able to utilize a wide range of amino acids as sole growth substrates.

The results of our investigations of amidase and histidase suggest that there is a complex system of regulation of the histidine utilization enzymes which ensures that histidine is not degraded when] alternative carbon or nitrogen sources are available. This would conserve for protein synthesis small quantities of histidine which might be encountered in the natural environment together with adequate supplies of carbon and nitrogen compounds which could be used as growth substrates. But, if no other compounds were available, the control system would allow the rapid synthesis of the Hut enzymes. Acetamide, on the other hand, is not particularly useful for cell syntheses and a less elaborate control system has evolved which allows high levels of amidase to be synthesized in the presence of acetamide unless a compound like succinate is available. The residual amount of amidase synthesized in the presence of succinate is still sufficient for acetamide to be used as a nitrogen source, since the specific activity of this enzyme for acetamide is high, but it is insufficient for the utilization of a poor substrate such as lactamide even as a nitrogen source.

We are grateful to Dr P. F. Smyth for providing some of the experimental data on histidase synthesis by strain PACI. J.R.P. was on leave of absence from Glaxo Research Ltd.

\section{REFERENCES}

ARst, H. N. \& Cove, D. J. (1973). Nitrogen metabolite repression in Aspergillus nidulans. Molecular and General Genetics 126, I1 I-I4I.

Brammar, W. J. \& Clarke, P. H. (I964). Induction and repression of Pseudomonas aeruginosa amidase. Journal of General Microbiology 37, 307-319.

Brammar, W. J., Clarke, P. H. \& SkinNer, A. J. (1967). Biochemical and genetic studies with regulator mutants of the Pseudomonas aeruginosa 8602 amidase system. Journal of General Microbiology 47, $87-102$.

BRILL, W. J. \& MAGASANIK, B. (1969). Genetic and metabolic control of histidase and urocanase in Salmonella typhimurium strain 15-59. Journal of Biological Chemistry 244, 5392-5402.

de Crombrugghe, B., Chen, B., Anderson, W., Nissley, P., Gottesman, M., Pastan, I. \& Perlman, R. (197I). Lac DNA, RNA polymerase and cyclic AMP receptor protein, cyclic AMP, lac repressor and inducer are the essential elements for controlled lac transcription. Nature, New Biology 231, 139-142.

Hynes, M. J. (1970). Induction and repression of amidase enzymes in Aspergillus nidulans. Journal of Bacteriology ro3, $482-487$. 
HyNES, M. J. (1972). Mutants with altered glucose repression of amidase enzymes in Aspergillus nidulans. Journal of Bacteriology III, 71 7-722.

HYNES, M. J. (1974). Effect of ammonium, L-glutamate and L-glutamine on nitrogen catabolism in Aspergillus nidulans. Journal of Bacteriology 120, I I 16-I 123.

KelLy, M. (196I). An investigation of the action of Pseudomonas aeruginosa on amides and related compounds. Ph.D. Thesis, University of London.

Kelly, M. \& ClarKe, P. H. (1962). An inducible amidase produced by a strain of Pseudomonas aeruginosa. Journal of General Microbiology 27, 305-316.

LESSIE, T. G. \& NeIDHARDT, F. C. (1967). Formation and operation of the histidine-degrading pathway in Pseudomonas aeruginosa. Journal of Bacteriology 93, 1800-1810.

Lowry, O. H., Rosebrough, N. J., FarR, A. L. \& RANDall, R. J. (I95I). Protein measurements with the Folin phenol reagent. Journal of Biological Chemistry 193, 265-275.

Magasanik, B., Prival, M. J., Brenchley, J. E., Tyler, B. M., Deleo, A. B., Streicher, S. L., Bender, R. A. \& PARIS, C. G. (1974). Glutamine synthesis as a regulator of enzyme synthesis. Current Topics in Cellular Regulation 8, I19-1 38 .

PotTs, J. R. (1975). Histidine catabolism in Pseudomonas aeruginosa. Ph.D. Thesis, University of London.

Potrs, J. R. \& Clarke, P. H. (I974). The regulation of histidine catabolism in Pseudomonas aeruginosa. Society for General Microbiology Proceedings $\mathbf{1}, 63$.

Prival, M. J., Brenchley, J. E. \& MAgasanik, B. (1973). Glutamine synthetase and the regulation of histidase formation in Klebsiella aerogenes. Journal of Biological Chemistry 248, 4334-4344.

PRIVAL, M. J. \& MAGASANIK, B. (I97I). Resistance to catabolite repression of histidase and proline oxidase during nitrogen-limited growth. Journal of Biological Chemistry 246, 6288-6296.

SMYTH, P. F. (1974). Catabolite repression in Pseudomonas aeruginosa. Ph.D. Thesis, University of London.

Smyth, P. F. \& Clarke, P. H. (1975a). Catabolite repression of Pseudomonas aeruginosa amidase: The effect of carbon sources on amidase synthesis. Journal of General Microbiology 9o, 8I-90.

SMYth, P. F. \& CLARKe, P. H. (1975 b). Catabolite repression in Pseudomonas aeruginosa amidase: Isolation of promotor mutants. Journal of General Microbiology 9o, $9 \mathrm{I}-99$.

Tronick, S. R., Ciardi, J.E. \& Stadtman, E. R. (I973). Comparative biochemical and immunological studies of bacterial glutamine synthetases. Journal of Bacteriology II5, 858-868.

Tyler, B., Deleo, A. B. \& Magasanik, B. (1974). Activation of hut DNA by glutamine synthetase. Proceedings of the National Academy of Sciences of the United States of America 7r, 225-229 